\title{
Spatiotemporal Variations of Land Use/Cover Changes in Inner Mongolia (China) during 1980-2015
}

\author{
Siqin Tong ${ }^{1,2,+}$, Zhenhua Dong ${ }^{1,+}{ }^{+}$, Jiquan Zhang ${ }^{1,2, *}$, Yongbin Bao ${ }^{1}$, Ari Guna ${ }^{1}$ and Yuhai Bao ${ }^{3}$ \\ 1 School of Environment, Northeast Normal University, Changchun 130024, China; \\ tongsq223@nenu.edu.cn (S.T.); dongzh103@nenu.edu.cn (Z.D.); baoyb924@nenu.edu.cn (Y.B.); \\ argn078@nenu.edu.cn (A.G.) \\ 2 Laboratory for Vegetation Ecology, Ministry of Education, Changchun 130024, China \\ 3 Geography, Inner Mongolia Normal University, Hohhot 010022, China; baoyuhai@imnu.edu.cn \\ * Correspondence: zhangjq022@nenu.edu.cn; Tel.: +86-135-9608-6467 \\ + Siqin Tong and Zhenhua Dong equally contributed to this work.
}

Received: 6 November 2018; Accepted: 5 December 2018; Published: 12 December 2018

\begin{abstract}
Land use/cover change (LUCC) is one of the major environmental changes and has become a hot topic in the study of global change. Based on four land use classification maps, this study used the intensity analysis method to quantitatively monitor the land use changes which occurred in Inner Mongolia during 1980-2015. The results showed that changes occurred although the trends of corresponding land use types were different (increase or decrease), and the land use changes had an obvious increasing or decreasing trend before and after 2000, respectively. Generally, woodland, high-coverage grassland, and moderate-coverage grassland decreased and the other land use types increased during 1980-2015. In addition, the changes had great differences in spatial distribution. The area of grassland had the largest decrease, indicating that the quality of grassland has declined in Inner Mongolia. The variation rate of land use in 1980-1990 was faster than the rates in 1990-2000 and 2000-2015.
\end{abstract}

Keywords: land use/cover change; spatiotemporal variation; intensity analysis; Inner Mongolia

\section{Introduction}

Land use and land cover change (LULCC) is an important part of global climate change and global environmental change research [1,2]. It is the most direct signal representing the behavior of human activities on the earth's surface natural ecosystems, and is the link between human social economic activities and natural ecological processes [1]. It is also closely related to the terrestrial surface material cycle and life processes [3]. This directly affects the biosphere-atmosphere interaction, biodiversity, surface radiation intensity, biogeochemical cycle, and the sustainable utilization of the resource environment [4]. The International Geosphere-Biosphere Programme (IGBP) and the International Human Dimensions Programme on Global Environmental Change (IHDP) jointly formulated the scientific research plan of Land Use/Cover Change (LUCC) in 1993, and declared that LUCC was the core content of global change research [5]. On this basis, the Global Land Project (GLP) was launched in 2005, emphasizing the comprehensive integration and simulation of the human-environment coupling system in the terrestrial system. The monitoring and simulation of the land use/land cover dynamic process based on the human-environment coupling system has become the focus of research $[6,7]$, and a hot issue in the field of Land Change Science (LCS) [8,9].

A land use transition matrix can be used to analyze the quantitative structure characteristics of regional land use change and the direction of local change [10-13], thus it has great significance in land use change and simulation and has been widely applied [14,15]. However, the transition 
matrix can only detect the changing area and does not reveal the intrinsic interaction between human and environment in the process of change, nor can it systematically evaluate over a continuous time interval for further study $[13,16]$. There are also indicators such as a landscape change index and a dynamic degree model related to the rate of changes in land use [17-19]. In 2012, Aldwaik and Pontius proposed an intensity analysis to calculate the intensity of land use changes at different time intervals, which is able to detect the rate of land use change [20]. It can be used to answer the following three questions: (1) For a certain time period, is the total annual change of land use/cover fast or slow? (2) Based on the above answer, are the different levels of land use/cover changes active or dormant? (3) Which of the former two answers is dominant in the process of the mutual transformation of the different categories of land use/cover? To date, many scholars have used the intensity analysis method to conduct research. Specifically, Huang et al. [21] and Zhou et al. [22] combined the intensity analysis with the change process of land use, and analyzed the spatiotemporal dynamic change and change process of land use in the Jiulong River Basin in the southeast coastal area of China. Mallinis et al. [23] conducted a comparative study on land use/cover change in Parnitha and Penteli over 62 recent years on multiple levels by using intensity analysis. However, although this method is basically mature, domestic scholars have not yet used it to study land use changes.

Inner Mongolia has one of the largest grasslands in China which is an important ecological barrier in the north of China. It is also an important agricultural and animal husbandry production base and one of the most sensitive zones of global change in China [24]. Since the mid-1980s, the problems of cultivated land reclamation, grassland degradation, and desertification have become more and more serious in this region, which are influenced by the purchase and sale system and price of agricultural products, regional climate warming, and the drying trend. The regional land use/cover change has attracted much attention in recent decades. Xu et al. [25] explored the land use change in Xilingol, Inner Mongolia from 1995 to 2000 and investigated the relationship between climate, topography, location, and human activities using canonical correspondence analysis; it found that grassland degraded and that topographic factors played a prominent role in determining the spatial distribution of grassland. Zhan et al. [26] examined the land use changing characteristics of the agro-pastoral ecotone in Inner Mongolia based on Landsat remote sensing data in the late 1980s and 1990s, and found that the arable land continued the trend of expansion with a relatively high speed at the cost of the severe loss of forest land, grassland, and unused land. Based on Landsat TM (Thematic Mapper)/ETM+ (Enhanced Thematic Mapper Plus) images, Zhang et al. [27] investigated the land use change in the forest-steppe ecotone of Inner Mongolia in 1980 and 2000. Zhang et al. [28] explored the land use changing characteristics, speed, process, and dynamics of landscape in the Hetao irrigation district of Inner Mongolia using a transfer matrix from 1985 to 2000. These research studies focus on the simple area change of land use in a certain region or the whole area in a short period of time. It does not consider the spatiotemporal changing characteristics and rates of land use in the whole region and each region at every stage over a long period of time, as well as the conversion rules among various land use types.

In the past half century, the combined effects of violent human activities, irrational land use, and global climate change have led to the degradation of vegetation, decrease of productivity, erosion and desertification of land, aggravated soil and water loss, and the frequent occurrence of pest disasters, sandstorm raging, and ecosystem dysfunction. These will seriously threaten the survival and development of local people, and endanger the ecological security in North China and other regions [29]. Clarifying the spatial and temporal dynamic changing characteristics of land use in Inner Mongolia is important for providing a scientific basis and support for the rational development of land resources and regional grassland ecological management. Therefore, based on four land use classification maps, this study used the intensity analysis method to quantitatively monitor the land use changes which occurred in Inner Mongolia during 1980-2015. 


\section{Data and Methods}

\subsection{Study Area}

The Inner Mongolia autonomous region was selected as the study area. It is located in the northern part of the People's Republic of China and lies between $37^{\circ} 24^{\prime} \mathrm{N}$ and $53^{\circ} 23^{\prime} \mathrm{N}$ and $97^{\circ} 12^{\prime} \mathrm{E}$ and $126^{\circ} 04^{\prime} \mathrm{E}$ (see Figure $1 \mathrm{a}$ ). It has a total area of approximately 1.18 million $\mathrm{km}^{2}$, which occupies $12.3 \%$ of China's total area and makes it the third largest province in China. Inner Mongolia includes 12 prefectural regions. It is under the influence of the East Asian monsoon because it falls within the zone of transition between humid and semi-humid monsoon climate and arid and semi-arid climate [30]. The annual mean air temperature progressively increases from approximately $-4.5^{\circ} \mathrm{C}$ in the northeast to $9.8^{\circ} \mathrm{C}$ in the southwest (see Figure $1 \mathrm{~b}$ ), but the annual precipitation decreases from the northeast to the southwest (see Figure 1b). In addition, the elevation increases from the northeast to the southwest, ranging from $86 \mathrm{~m}$ to $3526 \mathrm{~m}$. Due to the gradient in rainfall and temperature, its vegetation types, from the east to the west, are forest, grassland, and desert [31].
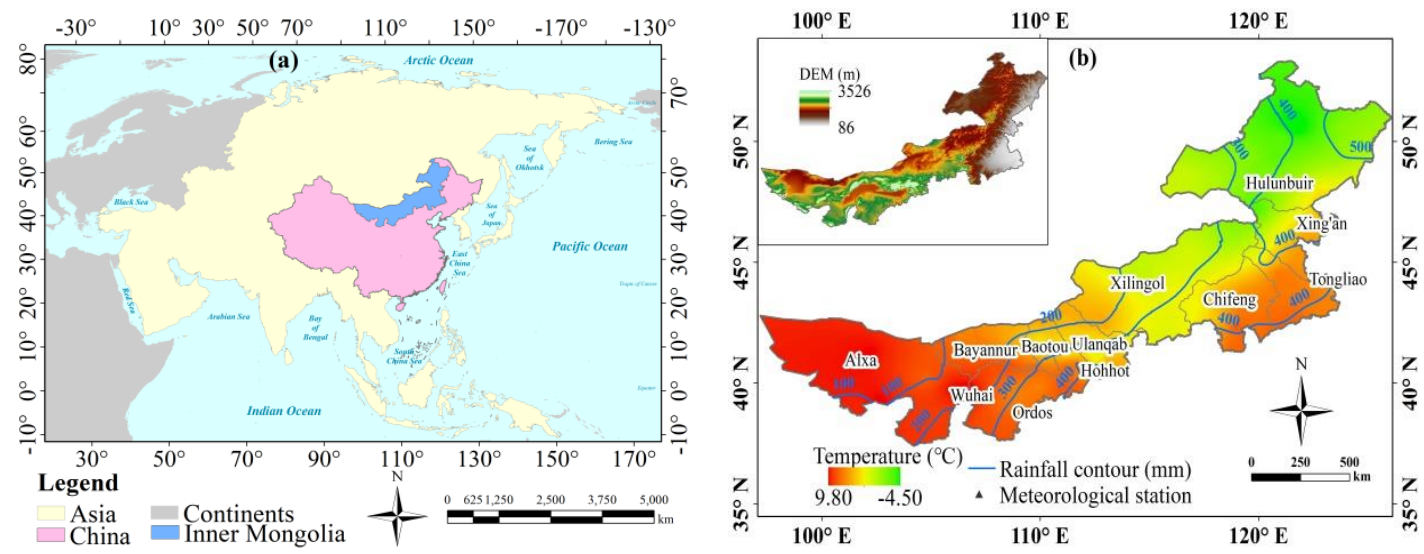

Figure 1. (a) Geographical location of the study area and (b) spatial distributions of annual mean temperature and precipitation, and elevation.

\subsection{Data Sources}

The Data Center for Resources and Environmental Sciences, Chinese Academy of Sciences (RESDC) (http:/ / www.resdc.cn) provided $1 \mathrm{~km}$ raster data of land use in 1980, 1990, 2000, and 2015. This dataset used Landsat TM/ETM+ and Landsat 8 remote sensing images to obtain the land use/land cover data in China. Its acquisition included four steps, namely, image preprocessing, human-machine interaction interpretation, dynamic information extraction, and field investigation verification.

The dataset starts with the national land use database with a scale of 1:100,000 using the fast extraction method of human-computer interaction based on remote sensing, and then updates to the database every five years. The specific operation, for example, is as follows: by comparing the images of 2005 and 2010, based on the land use classification data of 2005, the dynamic information coding of land use change is determined and plotted, which reflects the land use types of the changed land in 2005 and 2010 at the same time. In order to ensure the interpretation quality and consistency of the acquired data, unified quality check and data integration are carried out for each dataset. A large number of field survey records and photographs are obtained in the early stage of each dataset research and development, mostly autumn in the north area and spring in the south area. Then, the accuracy of field survey and field records is verified by random sampling according to the proportion of $10 \%$ counties. The accuracy of the comprehensive evaluation of land use classification in grade 1 is higher than $94.3 \%$, it is $91.2 \%$ in grade 2 , and the discrimination of land use change mapping achieves more than $95 \%$ qualitative accuracy. This dataset provides convenient and effective data support for the study of land use changes and is widely used by many scholars [32,33]. Based on the actual situation of Inner Mongolia and for research purposes, the data can be merged into nine main land use categories, 
namely, cropland, woodland, high-coverage grassland, moderate-coverage grassland, low-coverage grassland, water, built-up, sandy land, and unused land (see Table 1).

Table 1. Classification system of land use in Inner Mongolia.

\begin{tabular}{|c|c|c|c|}
\hline Code & Categories & Abbreviation & Description \\
\hline 1 & Cropland & $\mathrm{CL}$ & $\begin{array}{l}\text { Refers to dry land, generally no irrigation facilities and the population } \\
\text { relies on natural precipitation to cultivate dry crops. }\end{array}$ \\
\hline 2 & Woodland & WL & $\begin{array}{l}\text { Includes wood land, shrubbery land, sparsely forested woodland, } \\
\text { afforestation land, and slashes. }\end{array}$ \\
\hline 3 & $\begin{array}{l}\text { High-coverage } \\
\text { grassland }\end{array}$ & HCG & $\begin{array}{l}\text { Vegetation coverage is higher than } 50 \% \text {, including natural grassland, } \\
\text { improved grassland, and mowing grassland; better water condition } \\
\text { and the grass is dense. }\end{array}$ \\
\hline 4 & $\begin{array}{l}\text { Moderate-coverage } \\
\text { grassland }\end{array}$ & MCG & $\begin{array}{l}\text { Vegetation coverage ranges from } 20 \% \text { to } 50 \% \text {, including natural } \\
\text { grassland and improved grassland; lacks water and the grass is sparse. }\end{array}$ \\
\hline 5 & $\begin{array}{l}\text { Low-coverage } \\
\text { grassland }\end{array}$ & LCG & $\begin{array}{l}\text { Natural grassland refers to the vegetation coverage ranging from } 5 \% \text { to } \\
20 \% \text {, lack of water, the grass is sparse and the utilization condition of } \\
\text { livestock is poor. }\end{array}$ \\
\hline 6 & Water & WA & $\begin{array}{l}\text { Natural terrestrial water and water conservancy facilities, including } \\
\text { river, lake, reservoir, pond, beaches, and flats. }\end{array}$ \\
\hline 7 & Built-up & BU & $\begin{array}{l}\text { Includes areas of cities and towns, residential quarters in rural areas, } \\
\text { isolated industrial and mining lands. }\end{array}$ \\
\hline 8 & Sandy land & SL & $\begin{array}{c}\text { Includes a large amount of quicksand, widely distributed dunes, } \\
\text { and no vegetation. }\end{array}$ \\
\hline 9 & Unused land & UL & Includes bare land, exposed rock land, saline-alkali land, and wetland. \\
\hline
\end{tabular}

\subsection{Intensity Analysis}

The intensity analysis method was proposed by Aldwaik and Pontius in 2012 to quantitatively analyze land use and land cover changes. It is a top-down hierarchical explanatory frame structure used to analyze variations among terrestrial types [34]. It gives a deeper understanding of the various land use types in different periods, and this interpretative framework has been widely used $[35,36]$. Intensity analysis makes the best use of a transition matrix to analyze the intensity of land changes at three levels-time interval, category, and transition in the same area at different time points.

The interval level explores the total change of each time interval and observes the changing area and intensity at different time intervals. It answers the following question: "For a certain time period, is the total annual change of land use/cover fast or slow?" It was calculated using Equations (1) and (2). Equation (1) defines the change intensity of $S_{t}$ of the whole study area in each time interval (i.e. the average annual change rate in T-1 time interval), which means that there is a change rate $S_{t}$ in each time interval, and Equation (2) gives the uniform line value for the time intensity analysis $\mathrm{U}$ :

$$
\begin{gathered}
\mathrm{S}_{\mathrm{t}}=\frac{\left\{\sum_{\mathrm{j}=1}^{\mathrm{J}}\left[\left(\sum_{\mathrm{i}=1}^{\mathrm{J}} \mathrm{C}_{\mathrm{tij}}\right)-\mathrm{C}_{\mathrm{tij}}\right]\right\} /\left[\sum_{\mathrm{j}=1}^{\mathrm{J}} \sum_{\mathrm{i}=1}^{\mathrm{J}} \mathrm{C}_{\mathrm{tij}}\right]}{\mathrm{Y}_{\mathrm{t}+1}-\mathrm{Y}_{\mathrm{t}}} \times 100 \% \\
\mathrm{U}=\frac{\sum_{\mathrm{t}=1}^{\mathrm{T}-1}\left\{\sum_{\mathrm{j}=1}^{\mathrm{J}}\left[\left(\sum_{\mathrm{i}=1}^{\mathrm{J}} \mathrm{C}_{\mathrm{tij}}\right)-\mathrm{C}_{\mathrm{tij}}\right]\right\} /\left[\sum_{\mathrm{j}=1}^{\mathrm{J}} \sum_{\mathrm{i}=1}^{\mathrm{J}} \mathrm{C}_{\mathrm{tij}}\right]}{\mathrm{Y}_{\mathrm{T}}-\mathrm{Y}_{1}} \times 100 \%,
\end{gathered}
$$

where $C_{t i j}$ is the number of pixels transformed from time point $Y_{t}$ on level $i$ to time point $Y_{t+1}$ on level $\mathrm{j}$ (the same as below), $\mathrm{J}$ is the total land use category (the same as below), $\mathrm{T}$ is the total number of time points, $Y_{t}$ is the year of time point $t$ (the same as below), subscript $t$ is a certain time point within the range [1, $\mathrm{T}-1]$, subscript $\mathrm{i}$ represents the land use category at the initial time point of a certain time interval, and subscript $j$ is the land use category at the end time point of a certain time interval.

The category level calculates the total decrease and increase of the observed area and intensity of each land type change, and then compares the change intensity with uniform intensity. It answers 
the following question: 'Are the different levels of land use/cover changes active or dormant?' It was calculated using Equations (3) and (4), which give the intensity of increase and decrease, respectively:

$$
\begin{aligned}
\mathrm{G}_{\mathrm{tj}} & =\frac{\left[\left(\sum_{\mathrm{i}=1}^{\mathrm{J}} \mathrm{C}_{\mathrm{tij}}\right)-\mathrm{C}_{\mathrm{tij}}\right] /\left(\mathrm{Y}_{\mathrm{t}+1}-\mathrm{Y}_{\mathrm{t}}\right)}{\sum_{\mathrm{i}=1}^{\mathrm{J}} \mathrm{C}_{\mathrm{tij}}} \times 100 \% \\
\mathrm{~L}_{\mathrm{ti}} & =\frac{\left[\left(\sum_{\mathrm{j}=1}^{\mathrm{J}} \mathrm{C}_{\mathrm{tij}}\right)-\mathrm{C}_{\mathrm{tii}}\right] /\left(\mathrm{Y}_{\mathrm{t}+1}-\mathrm{Y}_{\mathrm{t}}\right)}{\sum_{\mathrm{j}=1}^{\mathrm{J}} \mathrm{C}_{\mathrm{tij}}} \times 100 \%
\end{aligned}
$$

where $G_{t j}$ is the annual total increasing intensity of level $j$ in $\left[Y_{t}, Y_{t+1}\right]$ and $L_{t i}$ is the annual total decreasing intensity of level $\mathrm{i}$ in $\left[\mathrm{Y}_{\mathrm{t}}, \mathrm{Y}_{\mathrm{t}+1}\right]$.

The transition level investigates the arbitrary intensity of transformation from one specific land type to another, and explains the size of change area of all individual land types in the whole study area. It answers the third question: "Which is dominant in the process of the mutual transformation of the different categories of land use/cover?":

$$
\mathrm{W}_{\mathrm{tn}}=\frac{\left[\left(\sum_{\mathrm{i}=1}^{\mathrm{J}} \mathrm{C}_{\mathrm{tin}}\right)-\mathrm{C}_{\mathrm{tnn}}\right] /\left(\mathrm{Y}_{\mathrm{t}+1}-\mathrm{Y}_{\mathrm{t}}\right)}{\sum_{\mathrm{j}=1}^{\mathrm{J}}\left[\left(\sum_{\mathrm{i}=1}^{\mathrm{J}} \mathrm{C}_{\mathrm{tij}}\right)-\mathrm{C}_{\mathrm{tnj}}\right]} \times 100 \%
$$

where $W_{t n}$ is the uniform intensity of transformation at time point $Y_{t}$ from a non- $n$ level to level $n$ in $\left[\mathrm{Y}_{\mathrm{t}}, \mathrm{Y}_{\mathrm{t}+1}\right]$ and subscript $\mathrm{n}$ represents the land use category transformed from other levels;

$$
\mathrm{R}_{\mathrm{tin}}=\frac{\mathrm{C}_{\mathrm{tin}} /\left(\mathrm{Y}_{\mathrm{t}+1}-\mathrm{Y}_{\mathrm{t}}\right)}{\sum_{\mathrm{j}=1}^{\mathrm{J}} \mathrm{C}_{\mathrm{tij}}} \times 100 \%
$$

where $R_{t i n}$ is the annual transformation intensity from level i to level $n(i \neq n)$ in $\left[Y_{t}, Y_{t+1}\right]$;

$$
\mathrm{V}_{\mathrm{tm}}=\frac{\left[\left(\sum_{\mathrm{j}=1}^{\mathrm{J}} \mathrm{C}_{\mathrm{tmj}}\right)-\mathrm{C}_{\mathrm{tmm}}\right] /\left(\mathrm{Y}_{\mathrm{t}+1}-\mathrm{Y}_{\mathrm{t}}\right)}{\sum_{\mathrm{i}=1}^{\mathrm{J}}\left[\left(\sum_{\mathrm{j}=1}^{\mathrm{J}} \mathrm{C}_{\mathrm{tij}}\right)-\mathrm{C}_{\mathrm{tim}}\right]} \times 100 \%
$$

where $V_{t m}$ is the uniform intensity of the transformation of time point $Y_{t+1}$ from level $m$ to all non-m levels in $\left[Y_{t}, Y_{t+1}\right]$, and subscript $m$ is the variation between the land use category and other levels;

$$
\mathrm{Q}_{\mathrm{tmj}}=\frac{\mathrm{C}_{\mathrm{tmj}} /\left(\mathrm{Y}_{\mathrm{t}+1}-\mathrm{Y}_{\mathrm{t}}\right)}{\sum_{\mathrm{i}=1}^{\mathrm{J}} \mathrm{C}_{\mathrm{tij}}} \times 100 \%
$$

where $Q_{t m j}$ is the annual transformation intensity from level $m$ to level $j(m \neq j)$ in $\left[Y_{t}, Y_{t+1}\right]$.

Based on the distribution of the time points, intensity analysis requires the classification criteria to be consistent at each time point. Therefore, according to the spatial distribution of land use status in Inner Mongolia, we defined the years 1980, 1990, 2000, and 2015 as the four time points and then classified the land use at different times according to Table 1. ArcGIS was used to obtain the land use transition matrix (see Table 2) at three time intervals (1980-1990, 1990-2000, and 2000-2015) to satisfy the premise of intensity analysis. 
Table 2. Transition matrix of land use types in Inner Mongolia for three time intervals by area $\left(\mathrm{km}^{2}\right)$ : 1980-1990 (in italics), 1990-2000 (underlined), and 2000-2015 (in bold).

\begin{tabular}{|c|c|c|c|c|c|c|c|c|c|c|c|c|}
\hline \multicolumn{11}{|c|}{ Final Year of Time Interval } & \multirow[t]{2}{*}{$\begin{array}{c}\text { Initial } \\
\text { Total }\end{array}$} & \multirow{2}{*}{$\begin{array}{c}\text { Gross } \\
\text { Loss }\end{array}$} \\
\hline \multicolumn{2}{|c|}{ Land Use Type } & CL & WL & HCG & MCG & LCG & WA & BU & SL & UL & & \\
\hline \multirow{27}{*}{$\begin{array}{l}\text { Initial year } \\
\text { of time } \\
\text { interval }\end{array}$} & \multirow[t]{3}{*}{$\mathrm{CL}$} & 96,921 & 1504 & 2212 & 2914 & 387 & 101 & 62 & 67 & 469 & 104,637 & 7716 \\
\hline & & 105,977 & $\underline{152}$ & $\underline{432}$ & $\underline{911}$ & $\underline{409}$ & $\underline{62}$ & $\underline{58}$ & $\underline{30}$ & $\underline{327}$ & $\underline{108,359}$ & $\underline{2382}$ \\
\hline & & $\overline{109,787}$ & $\overline{693}$ & $\overline{711}$ & $\overline{691}$ & $\overline{378}$ & $\overline{197}$ & $\overline{831}$ & $\overline{30}$ & $\overline{135}$ & $\overline{113,453}$ & $\overline{3666}$ \\
\hline & \multirow[t]{3}{*}{ WL } & 1311 & 162,523 & 634 & 2284 & 110 & 8 & 5 & 9 & 72 & 166,957 & 4434 \\
\hline & & $\underline{2338}$ & 162,747 & $\underline{431}$ & $\underline{181}$ & $\underline{82}$ & $\underline{12}$ & $\underline{17}$ & $\underline{4}$ & $\underline{28}$ & 165,840 & $\underline{3093}$ \\
\hline & & $\overline{332}$ & $\overline{162,211}$ & $\overline{389}$ & $\overline{188}$ & $\overline{124}$ & $\overline{63}$ & $\overline{106}$ & 30 & $\overline{80}$ & $\overline{163,523}$ & $\overline{1312}$ \\
\hline & \multirow[t]{3}{*}{ HCG } & 5481 & 1149 & 237,705 & 1406 & 367 & 40 & 48 & 88 & 387 & 246,671 & 8966 \\
\hline & & $\underline{2674}$ & $\underline{284}$ & 235,019 & $\underline{3011}$ & $\underline{2253}$ & $\underline{147}$ & $\underline{53}$ & $\underline{240}$ & $\underline{475}$ & 244,159 & $\underline{9140}$ \\
\hline & & $\overline{1582}$ & $\overline{1206}$ & $\overline{229,096}$ & $\overline{2652}$ & $\overline{1423}$ & $\overline{162}$ & $\overline{655}$ & $\overline{329}$ & $\overline{307}$ & $\overline{237,412}$ & $\overline{8316}$ \\
\hline & \multirow[t]{3}{*}{ MCG } & 3203 & 459 & 1796 & 177,846 & 638 & 31 & 40 & 159 & 149 & 184,321 & 6475 \\
\hline & & $\underline{1422}$ & $\underline{138}$ & $\underline{879}$ & 180,513 & $\underline{1913}$ & $\underline{82}$ & $\underline{40}$ & $\underline{757}$ & $\underline{402}$ & 186,146 & $\underline{5633}$ \\
\hline & & 856 & 440 & 3578 & 176,242 & 2543 & 152 & 746 & 972 & 343 & 185,972 & 9630 \\
\hline & \multirow[t]{3}{*}{ LCG } & 589 & 88 & 1149 & 937 & 101,163 & 15 & 5 & 489 & 1361 & 105,796 & 4633 \\
\hline & & $\underline{319}$ & $\underline{115}$ & $\underline{249}$ & $\underline{517}$ & 100,777 & $\underline{31}$ & $\underline{20}$ & $\underline{1169}$ & $\underline{280}$ & 103,477 & $\underline{2700}$ \\
\hline & & $\overline{459}$ & $\overline{217}$ & $\overline{1096}$ & $\overline{1544}$ & $\overline{100,997}$ & $\overline{91}$ & $\overline{460}$ & $\overline{1103}$ & $\overline{259}$ & $\overline{106,226}$ & $\overline{5229}$ \\
\hline & \multirow[t]{3}{*}{ WA } & 206 & 22 & 84 & 71 & 19 & 13,459 & 4 & 15 & 229 & 14,109 & 650 \\
\hline & & $\underline{49}$ & $\underline{4}$ & $\underline{12}$ & $\underline{24}$ & $\underline{11}$ & $\underline{13,657}$ & $\underline{5}$ & $\underline{6}$ & $\underline{162}$ & $\underline{13,930}$ & $\underline{273}$ \\
\hline & & $\overline{191}$ & 37 & $\overline{45}$ & $\overline{129}$ & $\overline{129}$ & $\overline{12,942}$ & $\overline{47}$ & 392 & $\overline{586}$ & $\overline{14,498}$ & $\overline{1556}$ \\
\hline & \multirow[t]{3}{*}{$\mathrm{BU}$} & 26 & 15 & 29 & 27 & 3 & 4 & 10,786 & 1 & 5 & 10,896 & 110 \\
\hline & & $\underline{0}$ & $\underline{0}$ & $\underline{0}$ & $\underline{0}$ & $\underline{0}$ & $\underline{0}$ & $\underline{10,963}$ & $\underline{0}$ & $\underline{0}$ & $\underline{10,963}$ & $\underline{0}$ \\
\hline & & $\overline{48}$ & $\overline{11}$ & $\overline{8}$ & 24 & $\overline{15}$ & $\overline{19}$ & $\overline{11,027}$ & 3 & $\overline{13}$ & $\overline{11,168}$ & $\overline{141}$ \\
\hline & \multirow[t]{3}{*}{ SL } & 42 & 15 & 169 & 341 & 540 & 18 & 2 & 141,952 & 40 & 143,119 & 1167 \\
\hline & & $\underline{86}$ & $\underline{39}$ & $\underline{106}$ & $\underline{348}$ & $\underline{566}$ & $\underline{27}$ & $\underline{3}$ & $\underline{141,714}$ & $\underline{78}$ & 142,967 & $\underline{1253}$ \\
\hline & & $\overline{98}$ & $\overline{240}$ & $\overline{166}$ & $\overline{846}$ & $\overline{1356}$ & $\overline{94}$ & $1 \overline{53}$ & $\overline{140,923}$ & $\overline{60}$ & $\overline{143,936}$ & $\overline{3013}$ \\
\hline & \multirow[t]{3}{*}{ UL } & 579 & 65 & 379 & 320 & 250 & 254 & 11 & 187 & 163,659 & 165,704 & 2045 \\
\hline & & $\underline{588}$ & $\underline{44}$ & $\underline{284}$ & $\underline{367}$ & $\underline{215}$ & $\underline{480}$ & $\underline{9}$ & $\underline{16}$ & 164,368 & 166,371 & $\underline{2003}$ \\
\hline & & $\overline{317}$ & $\overline{78}$ & $\overline{249}$ & $\overline{873}$ & $\overline{579}$ & $\overline{449}$ & 387 & $\overline{33}$ & $\overline{163,155}$ & $\overline{166,120}$ & $\overline{2965}$ \\
\hline Final & & 108,359 & 165,840 & 244,157 & 181,646 & 103,477 & 13,930 & 10,963 & 142,967 & 166,371 & & \\
\hline \multirow[t]{2}{*}{ Total } & & 113,453 & 163,523 & 237,412 & 185,872 & 106,226 & 14,498 & 11,168 & 143,936 & 166,120 & & \\
\hline & & $\overline{113,670}$ & $\overline{165,134}$ & 235,338 & $\overline{183,191}$ & $\overline{107,545}$ & $\overline{14,169}$ & $\overline{14,412}$ & 143,815 & $\overline{164,938}$ & & \\
\hline \multirow{3}{*}{$\begin{array}{c}\text { Gross } \\
\text { gain }\end{array}$} & & 11,438 & 3317 & 6452 & 8300 & 2314 & 471 & 177 & 1015 & 2712 & & \\
\hline & & $\underline{7476}$ & $\underline{776}$ & $\underline{2393}$ & $\underline{5359}$ & $\underline{5449}$ & $\underline{841}$ & $\underline{205}$ & $\underline{2222}$ & $\underline{1752}$ & & \\
\hline & & $\overline{3883}$ & $\overline{2923}$ & $\overline{6242}$ & $\overline{6949}$ & $\overline{6548}$ & $\overline{1227}$ & $\overline{3385}$ & $\overline{2892}$ & $\overline{1783}$ & & \\
\hline
\end{tabular}

\section{Results}

\subsection{Land Use Distribution and Its Changes in Inner Mongolia during 1980-2015}

Figure 2 shows the land use status of Inner Mongolia in 1980, 1990, 2000, and 2015. It can be seen from the figure that there are spatially distributed woodland, grassland, and desert from the northeast to west, and cropland mainly distributed in the southeast and mid-west of Inner Mongolia. According to the area ratio, the land use types basically have a characteristic of grassland $>$ woodland $>$ unused land $>$ sandy land $>$ cropland $>$ water $>$ built-up, and grassland accounts for more than $45 \%$ of the total area.

From the area ratio bar graph of each land use type in the four time periods, we can see that the area of cropland has continuously increased from $9.16 \%$ in 1980 to $9.95 \%$ in 2015, and the degree of increase in 1980-2000 was larger than that in 2000-2015. Woodland decreased from 1980 to 2000, and then increased in 2015; the area of built-up is continually increasing and the largest increasing amplitude occurred in 2000-2015; the water and sandy land areas had the same changing tendency, that is, the area decreased from 1980 to 1990, increased in 1990-2000, and then decreased in 2000-2015; and the unused land area increased during 1980-2000 and then obviously decreased in 2000-2015. The total grassland area decreased and for the different grades of grassland, high-coverage grassland continuously decreased from 1980 to 2015, moderate-coverage grassland increased during 1980-2000 and then decreased to the lowest point in 2015, and low-coverage grassland decreased from 1980 to 1990 but remarkably increased from 1990 to 2015, indicating that the quality of grassland has declined in Inner Mongolia during 1980-2015. 


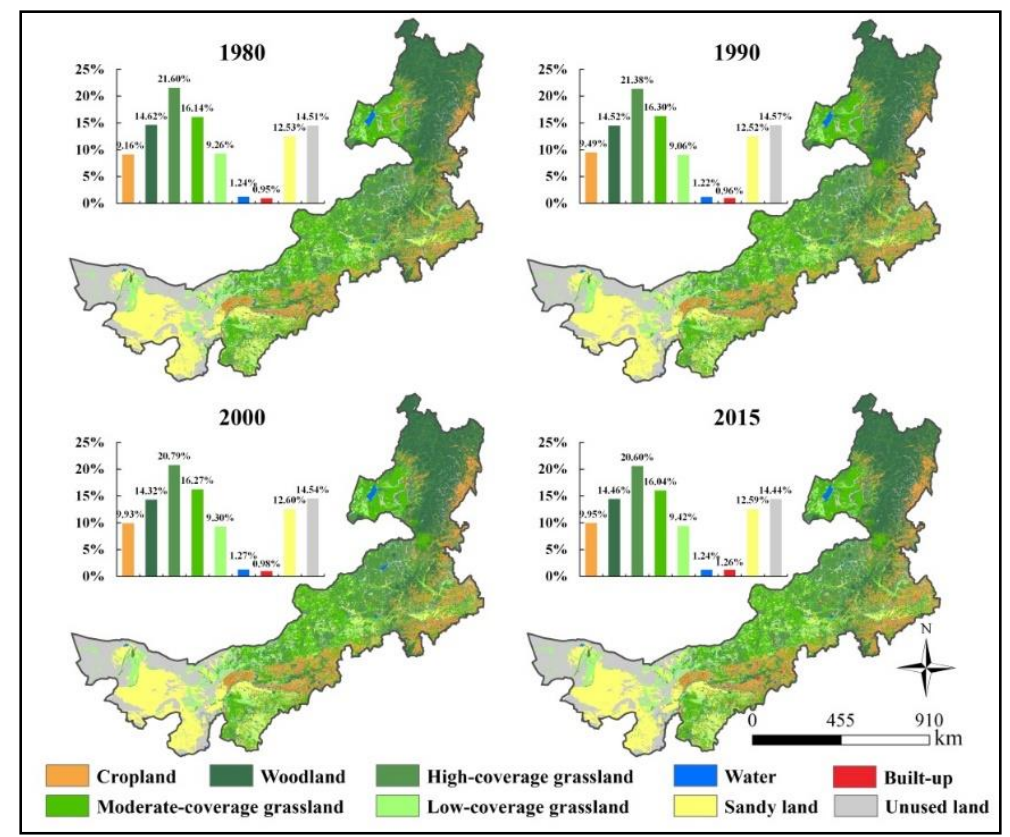

Figure 2. Land cover maps for Inner Mongolia in 1980, 1990, 2000, and 2015.

Figure 3 shows the spatial pattern of transferred out or added for each land use type from 1980 to 2015. We can see from Figure 3 a that $7530 \mathrm{~km}^{2}$ of cropland were transferred out to other types, whereas the area added by another land use type reached $16,347 \mathrm{~km}^{2}$, indicating that the area of cropland increased during 1980-2015. Contrary to cropland, the area of transferred out is larger than the added area in the case of woodland, indicating that the area of woodland decreased during 1980-2015. As Figure $3 \mathrm{~b}$ shows, it was reduced by approximately $1808 \mathrm{~km}^{2}$, and mainly distributed in the eastern part. The three grades of grassland, namely, high-coverage grassland, moderate-coverage grassland, and low-coverage grassland, are shown in Figure $3 \mathrm{c}-\mathrm{e}$, respectively. The area that was transferred out, in descending order, is high-coverage grassland $>$ moderate-coverage grassland $>$ low-coverage grassland. Briefly, the areas of high-coverage grassland and moderate-coverage grassland decreased during 1980-2015, especially the former, but the area of low-coverage grassland went in the opposite direction. This may be attributed to grassland degradation. There was almost no change in water during 1980-2015, as is shown in Figure 3f. It can be seen from Figure $3 g$ that $383 \mathrm{~km}^{2}$ of built-up were transferred out to other types, whereas the area added by another land use type reached $3771 \mathrm{~km}^{2}$, indicating that the area of built-up increased rapidly during 1980-2015. Geographically, sandy land and unused land are dominant on the western side. The area of sandy land increased, whereas unused land decreased (see Figure 3h,i).

Generally speaking, the areas of grassland and woodland were reduced, but cropland, built-up, and sandy land increased disproportionately, whereas high-coverage grassland suffered the most serious decrease. Meanwhile, cropland increased the most. The area of water remained stable during 1980-2015. 

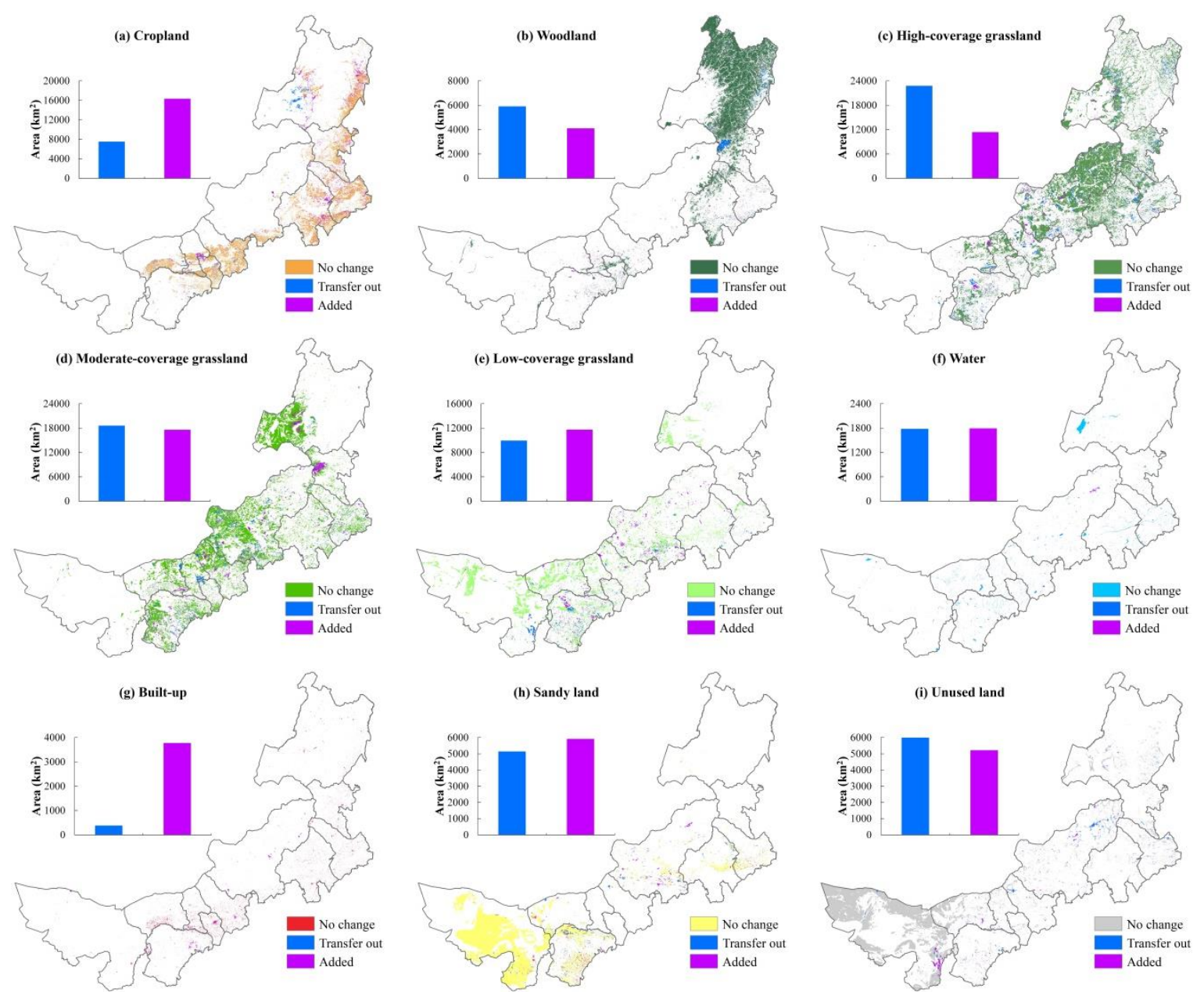

Figure 3. Transfer of land use/cover from 1980 to 2015 in Inner Mongolia (the bar graph indicates the area that is transferred out or added).

\subsection{Intensity Analysis Results of Land Use/Cover Changes in Inner Mongolia}

The results of the interval intensity analysis are shown in Figure 4, in which the bars on the left represent the overall scale of land use variation for each time interval, whereas the bars on the right represent the time intensity obtained using Equation (2). Additionally, the dashed line on the right is the uniform intensity line obtained using Equation (1). If the bar exceeds the uniform intensity line, the change in the land use in that time interval was relatively fast; otherwise, it was relatively slow. It can be seen from the figure that the bars on the right in 1980-1990 exceed the uniform intensity line, which indicates that the variation rate of land use in 1980-1990 was faster than that in 1990-2000 and 2000-2015, and the variation rate in 2000-2015 was relatively slow.

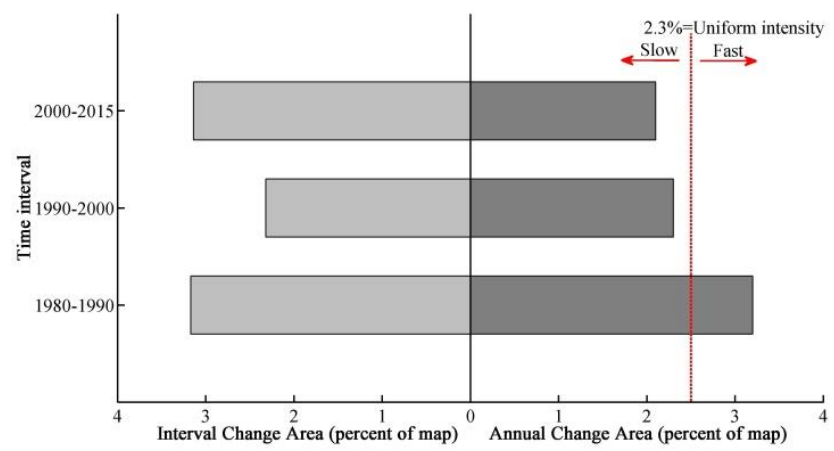

Figure 4. Interval intensity analysis for three time intervals: 1980-1990, 1990-2000, and 2000-2015. 
The category intensity analysis can answer the following question: "Which categories of land use/cover changes are relatively active and which categories are relatively dormant in a given time interval?" The results are shown in Figures 5-7. Each land use type is represented by a horizontal bar. The two panels in each figure, (a) and (b), represent the gross annual areas of gain and loss, respectively. The bars extending to the left of zero show the gross annual area of gain/loss in the study area, calculated using Equations (3) and (4), whereas the bars extending to the right of zero show the intensity of the annual gain/loss (the numerators of Equations (3) and (4)) within each category. The dashed line is the uniform intensity line: if a bar exceeds the uniform line, the change in land use category was relatively active in the given time interval; otherwise, it was relatively dormant.
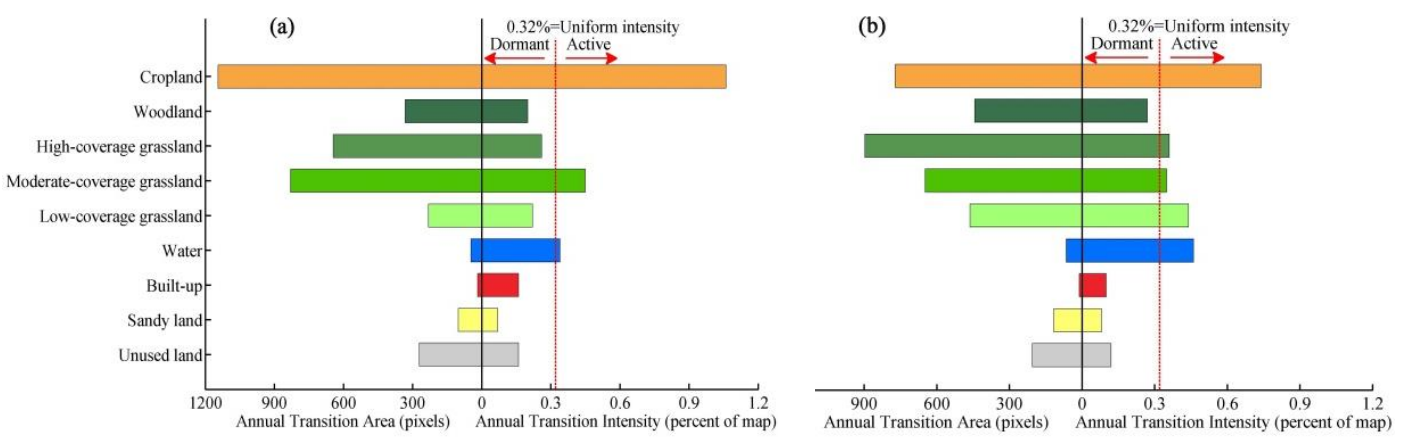

Figure 5. Category intensity analysis for 1980-1990, (a) for gains and (b) for losses.
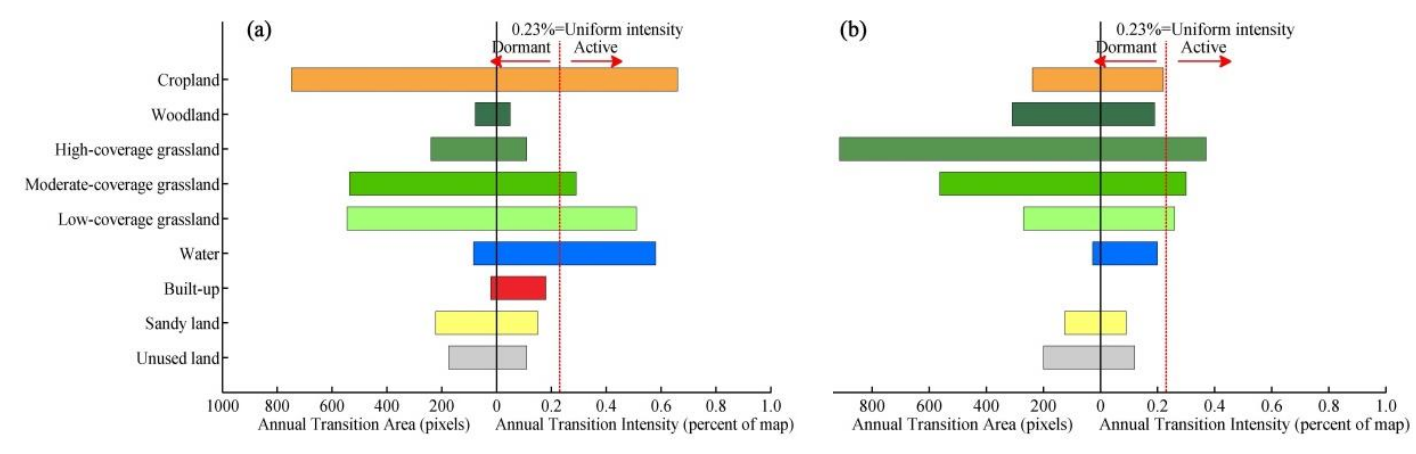

Figure 6. Category intensity analysis for 1990-2000, (a) for gains and (b) for losses.
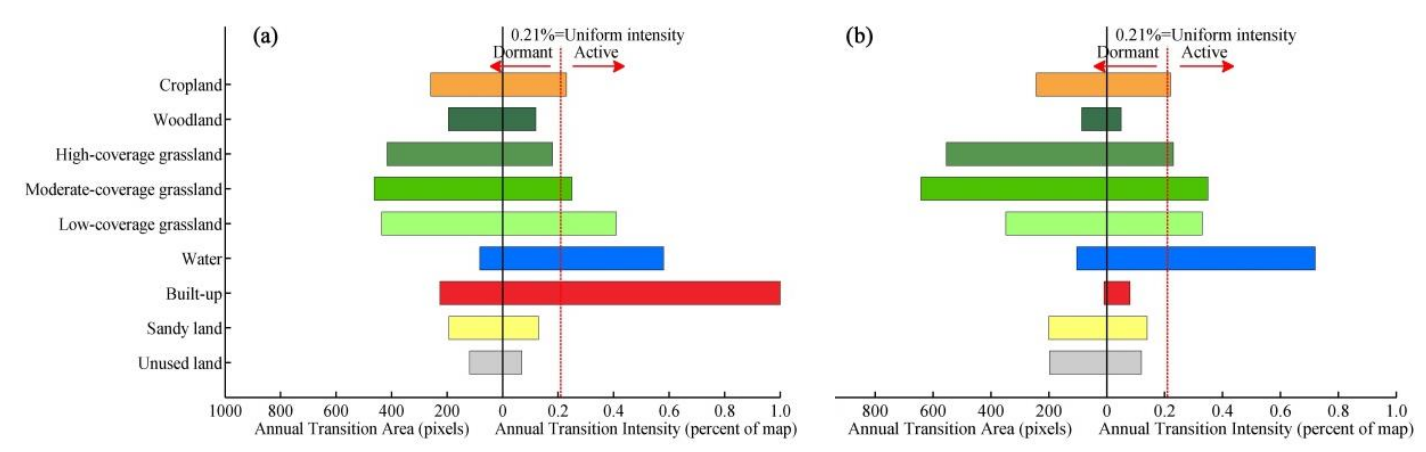

Figure 7. Category intensity analysis for 2000-2015, (a) for gains and (b) for losses.

Figure 5 is the category intensity analysis for 1980-1990. The annual transition change of cropland, moderate-coverage grassland, and water gains (see Figure 5a) and losses (see Figure 5b) were both active, and the changing area of gains was larger than losses in cropland and moderate-coverage grassland. The annual transition areas of high-coverage grassland and low-coverage grassland losses were much larger than gains and active. The area of loss in woodland was larger than the gain but dormant.

Figure 6 is the category intensity analysis for 1990-2000. The gains in cropland and water were active and the transition areas were larger than the losses. The transition area of loss in woodland was 
larger than its gain. The loss in high-coverage grassland was active and the decreasing area was much larger than the increasing area. The gains and losses in moderate-coverage grassland and low-coverage grassland were both active, and the gain in low-coverage grassland was much larger than the loss. The land use changes in 1990-2000 expressed as cropland, low-coverage grassland, water, built-up, and sandy land areas increased; woodland, high-coverage grassland, and sandy land areas decreased.

Figure 7 is the category intensity analysis for 2000-2015. For cropland, its gains and losses were both active. As for woodland, its gains and losses were both dormant. The loss in high-coverage grassland was active, and the gains and losses in moderate-coverage grassland, low-coverage grassland, and water were all active. It is worth mentioning that built-up had the largest intensity and the gains were obvious (see Figure 7a).

Table 3 shows the results of the transition intensity analysis, addressing the question "Which level was dominant in the transition process among the different categories of land use?" This study identified the dominant transition for each time interval to reveal the transition pattern between each land use category. As shown in the table, the dominant land use transition categories in the three time intervals were identical.

Table 3. Conversions of dominant land use during three time periods.

\begin{tabular}{|c|c|c|c|}
\hline Land Use Types & 1980-1990 & 1990-2000 & 2000-2015 \\
\hline Cropland & $+, \mathrm{HCG}, \mathrm{MCG}$ &,+ WL, HCG, MCG & -, HCG, MCG \\
\hline Woodland & $-, \mathrm{CL}, \mathrm{MCG}$ &,$- \mathrm{CL}$ & $+, \mathrm{CL}, \mathrm{HCG}$ \\
\hline High-coverage grassland &,$- \mathrm{CL}$ &,- CL, MCG, LCG &,- CL, MCG, LCG \\
\hline Moderate-coverage grassland & $+, C L, W L, L C G$ & -, CL, LCG & -, HCG, LCG, BU \\
\hline Low-coverage grassland & -, HCG, MCG, UL & $+, \mathrm{HCG}, \mathrm{MCG}$ & $+, \mathrm{MCG}, \mathrm{SL}$ \\
\hline Water &,$- \mathrm{UL}$ &,$+ \mathrm{UL}$ & $-, \mathrm{SL}, \mathrm{UL}$ \\
\hline Built-up &,$+ \mathrm{UL}$ &,$+ \mathrm{UL}$ & $+, \mathrm{CL}, \mathrm{UL}$ \\
\hline Sandy land &,+ LCG, WA, UL &,+ MCG, LCG & -, MCG, LCG, BU \\
\hline Unused land & $+, \mathrm{CL}, \mathrm{LCG}$ & +, CL, HCG, MCG, LCG &,- MCG, LCG, WA, BU \\
\hline
\end{tabular}

+ represents other categories of land use transfer into a certain category; - represents one transfer out to the other land categories.

In the 1980-1990 and 1990-2000 periods, cropland increased and was mainly caused by the high-coverage grassland and moderate-coverage grassland transition; on the other hand, in 2000-2015, cropland transferred out to grassland. Woodland was dominated by the transformation of being cropland and moderate-coverage grassland in the previous two periods, and then in 2000-2015 cropland and high-coverage grassland transferred into woodland. In 1980-1990, high-coverage grassland mainly transferred out to cropland; in 1990-2000 and 2000-2015, it mainly transferred out to cropland, moderate-coverage grassland, and low-coverage grassland. Moderate-coverage grassland increased in 1980-1990 and was mainly dominated by the conversion of cropland, woodland, and high-coverage grassland; whereas, in the other periods, it was transferred to another type of land use. The conversions of low-coverage grassland turned out to be high-coverage grassland or moderate-covered grassland in 1980-1990, and it transferred from them back to low-coverage grassland in 1990-2000 and 2000-2015. The conversion of water was mainly between unused lands. Built-up was mainly transferred from unused land during the three time periods. In 1980-1990 and 1990-2000, sandy land and unused land came from the other land use types, and then they transferred out to other types in 2000-2015, which involved all types of land use.

\subsection{Characteristics of Land Use/Cover Changes in Each Region}

Figure 8 shows the area change of the 9 land uses in 12 prefectural regions during the three study periods. It can be seen from Figure 8a that cropland decreased in 1980-1990 and then significantly increased from 1990 to 2000 reaching approximately $3428 \mathrm{~km}^{2}$ in Hulunbuir; woodland obviously decreased in 1990-2000 (about $2136 \mathrm{~km}^{2}$ ), and high-coverage grassland decreased in the three study periods; combined with the Table 4, we can see that the areas of woodland and grassland in Hulunbuir decreased over the period 1980-2015, whereas the other land uses increased, especially cropland. 
The land use change in Xing' an occurred mainly in 1980-1990; specifically, the area of cropland and low-coverage grassland increased and high-coverage grassland and moderate-coverage grassland decreased (see Figure $8 \mathrm{~b}$ ). The land use in Tongliao and Chifeng had similar changing characteristics: cropland increased in the three periods, with the largest increase in 1980-1990 (more than $2000 \mathrm{~km}^{2}$ ) and the lowest increase in 1990-2000. All of the grasslands decreased. Table 4 shows that, in Tongliao and Chifeng, the areas of cropland, woodland, and built-up increased and the other land uses decreased during 1980-2015 (see Figure 8c,d).
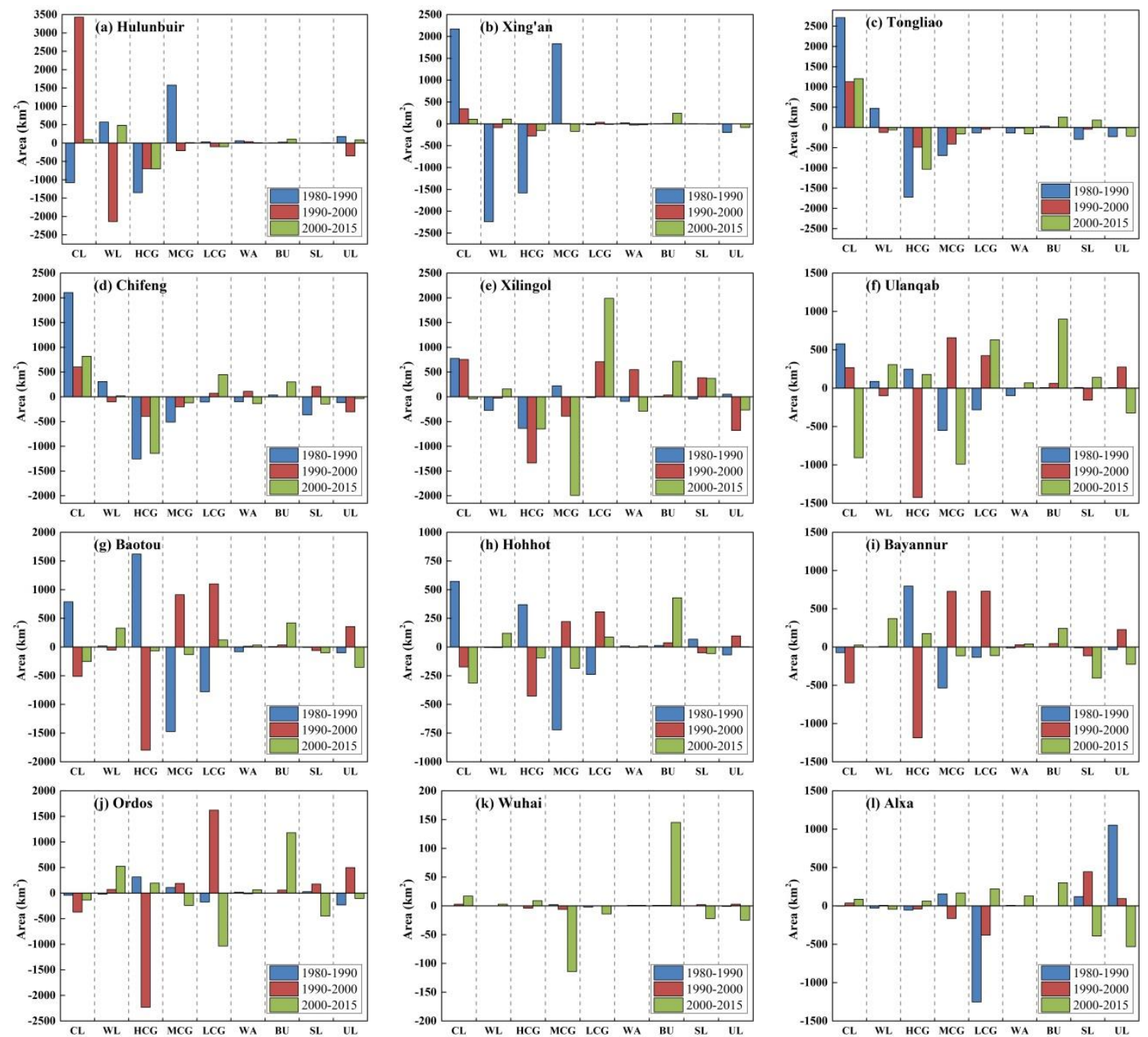

Figure 8. Area changes of land use in 12 prefectural regions during 1980-1990, 1990-2000, and 2000-2015.

Table 4. Area changes of land use in each region from 1980 to $2015\left(\mathrm{~km}^{2}\right)$.

\begin{tabular}{cccccccccc}
\hline & CL & WL & HCG & MCG & LCG & WA & BU & SL & UL \\
\hline Inner Mongolia & 9033 & -1823 & $-11,333$ & -1130 & 1749 & 60 & 3516 & 696 & -768 \\
Hulunbuir & 2446 & -1080 & -2755 & -2755 & -168 & 112 & 140 & 8 & -86 \\
Xing'an & 2622 & -2217 & -2013 & 1672 & 1 & -28 & 253 & -1 & -289 \\
Tongliao & 5044 & 285 & -3246 & -1272 & -177 & -314 & 296 & -157 & -459 \\
Chifeng & 3529 & 226 & -2791 & -836 & 414 & -124 & 339 & -300 & -457 \\
Xilingol & 1492 & -140 & -2622 & -2162 & 2682 & 166 & 764 & 715 & -895 \\
Ulanqab & -61 & 295 & -1001 & -888 & 770 & -30 & 967 & -9 & -43 \\
Baotou & 24 & 296 & -243 & -695 & 447 & -32 & 466 & -166 & -97 \\
Hohhot & 86 & 110 & -153 & -686 & 155 & 15 & 480 & -37 & 30 \\
Bayannur & -515 & 381 & -216 & 78 & 482 & 60 & 293 & -530 & -33 \\
Ordos & -548 & 577 & -1721 & 57 & 412 & 69 & 1240 & -245 & 159 \\
Wuhai & 20 & 3 & 5 & -118 & -16 & 2 & 147 & -20 & -23 \\
Alxa & 120 & -66 & -34 & 162 & -1413 & 140 & 305 & 173 & 613 \\
\hline
\end{tabular}


It is well known that Xilingol grassland is a large natural pasture in China; however, high-coverage grassland and moderate-coverage grassland decreased and low-coverage grassland increased in the study periods (see Figure 8e). This indicates that the quality of grass decreased to some extent over the past 36 years. The areas of high-coverage grassland and moderate-coverage grassland had the larger decline and were mainly transferred into woodland, low-coverage grassland, and built-up in Ulanqab (see Figure 8f). The land use in Baotou and Hohhot had similar changing characteristics; cropland and high-coverage grassland increased in 1980-1990 and decreased in the other two periods; moderate-coverage grassland and low-coverage grassland decreased in 1980-1990 and increased in 1990-2000 (see Figure 8g,h); sandy land, high-coverage grassland, and moderate-coverage grassland were transferred out to other types and built-up had the largest increase, especially in 2000-2015. In Bayannur, cropland decreased in 1990-2000, high-coverage grassland increased in 1980-1990 and 2000-2015 and decreased in 1990-2000, and moderate-coverage grassland and low-coverage grassland underwent the opposite changes (see Figure 8i). In Ordos, it was obvious that high-coverage grassland decreased and low-coverage grassland increased in 1990-2000, and built-up increased by $1180 \mathrm{~km}^{2}$ in 2000-2015 (see Figure 8j). Land use in Wuhai changed mainly after 2000 and the change was smaller (see Figure 8k). Alxa is a desert area and it can be seen from Figure 81 that high and low grassland decreased and the areas of cropland, sandy land, and unused land increased. For the whole Inner Mongolia, woodland, high-coverage grassland, and moderate-coverage grassland decreased, having areas of $1823 \mathrm{~km}^{2}, 11,333 \mathrm{~km}^{2}$, and $1130 \mathrm{~km}^{2}$, respectively, and the other land types increased during 1980-2015 (see Table 4).

\section{Discussion}

During the study period of 1980 to 2015, changes occurred although the trends of corresponding land use types were different (increase or decrease), and it was obvious that the changes were different before and after 2000. Generally, the areas of woodland, low-coverage grassland, and built-up increased and the other types decreased after 2000 in Inner Mongolia. Compared with the areas where urban and rural construction lands are significantly expanded in the Huanghai plain, the southeast coastal area, the Sichuan Basin, and the northwest and northeast China with a significant increase in dry land area [33], the forest area increased rapidly and the cropland area decreased at the beginning of the 21st century in Inner Mongolia, and this is similar to existing research results [37]. In addition, the area changes of grassland, water, built-up, sandy land, and unused land in the whole region also show significant temporal and spatial complexity, indicating that the causes affecting the dynamic change of land use in the study area are very complex, so land uses do not show the routine change trend. It was also shown that the grassland productivity and quality in the northern farming-pastoral transitional zone has decreased [14,38]. In contrast to the drastic change of land use caused by the increasing demand of urban and industrial development for construction land in eastern China, Beijing-Tianjin, and the Yangtze River Delta and Pearl River Delta regions of China [33], the land use change in Inner Mongolia is undoubtedly the result of both natural and human activities. Inner Mongolia is a typical arid and semi-arid area, and the land cover is more sensitive to climate change [39]. It can be seen from the existing research that climate change, social economic development, and regional ecological protection policies are the important driving forces of the land use change in Inner Mongolia [40-42]. Since the early 1980s, the rapid growth in the population and economy in Inner Mongolia has led to the unreasonable utilization of resources such as overgrazing and over-reclamation. This has led to the decline of grassland quality, the worsening of desertification and the deterioration of the ecological environment in the late 1990s, and resulting in the spring sandstorm disaster in northern China in 2000. In view of this, since 2000, the relevant departments have promoted the implementation of natural and ecological protection measures such as the Three-North Shelterbelt and Returning Farmland to Forest and Grassland projects. By 2005, $74.3 \times 10^{4} \mathrm{hm}^{2}$ of farmland had been converted and $124.9 \times 10^{4} \mathrm{hm}^{2}$ of forests had been planted, thereby restoring the macro-ecological environment of the whole region [41]. 
A comparison of the intensity analysis and the widely used Markov model to analyze the process of land use change found that the Markov model structure is a bottom-up process; the transformation intensity of each row of that model determines the change process of entire time interval. It calculates the proportion of land type at $\mathrm{T}$ to $\mathrm{T}+1$ time, and the change size at $\mathrm{T}$ is independent of the other types that are changing. The Markov model only considers the increasing transition intensity of specific land use type when compared with the increase and decrease pattern of the category level intensity analysis, and it also neglects the change size and rate among different land use types [43].

Generally speaking, intensity analysis not only emphasized the magnitude of the category changes but also revealed the intensity of the changes involving different levels. This method can be used to analyze the change speed of land use in each period. It can reflect the activity or dormancy of the overall changes in land use and the transition rules between different levels. Therefore, this method can be applied to the establishment of land use change rules. However, this method has many shortcomings and must be further improved. For example, this method does not consider data uncertainty or the influences of the overlap between different categories or the spatial distribution; therefore, spatial variation analysis remains inadequate. To solve these problems, the intensity analysis framework must be improved by adding information about spatial position into the analytical process so that both the spatial and temporal variation characteristics can be analyzed.

\section{Conclusions}

In this study, Inner Mongolia was selected as the study area. Based on the four time period land use classification data, the spatial and temporal variations of land use/cover changes in the whole region and in 12 prefectural regions over the past 35 years were comprehensively analyzed by using intensity analysis. The main conclusions of the study are as follows:

(1) There are spatially distributed woodland, grassland, and desert from the northeast to west, and cropland mainly distributed in the southeast and mid-west of Inner Mongolia; according to the area ratio, the land use types basically have a characteristic of grassland $>$ woodland $>$ unused land $>$ sandy land $>$ cropland $>$ water $>$ built-up, and grassland accounts for more than $45 \%$ of the total area.

(2) For the whole region, woodland, unused land, high-coverage grassland, and moderate-coverage grassland decreased and the other land types increased during 1980-2015, and the changes had great differences in spatial distribution; the area of grassland had the largest decrease, indicating that the quality of grassland has declined in Inner Mongolia; and these decreases came mainly from the typical animal husbandry regions like Hulunbuir, Xing'an, Tongliao, Chifeng and Xilingol.

(3) It is obvious that the changes were different before and after 2000. Generally, the areas of woodland, low-coverage grassland, and built-up increased and the other types decreased after 2000 in Inner Mongolia.

(4) The results of the intensity analysis show that the variation rate of land use in 1980-1990 was faster than the rates in 1990-2000 and 2000-2015. The gains of cropland were large in 1980-1990 and 1990-2000, whereas the losses were large in 2000-2015 and were both active; the losses of woodland were large in 1980-1990 and 1990-2000, and the losses were large in 2000-2015; the losses of high-coverage grassland were larger than its gains and both were active in the three periods; the losses of moderate-coverage grassland were active and larger than the gains in 1990-2000 and 2000-2015; the gains of low-coverage grassland were active in 1990-2000 and 2000-2015; the area of gains in water and sandy land were large in 1990-2000, whereas the losses were large in 2000-2015.

Author Contributions: All authors contributed significantly to this manuscript. J.Z. and Y.B. (Yuhai Bao) were responsible for the original idea and the theoretical aspects of the paper. Y.B. (Yongbin Bao) and A.G. were responsible for the data collection and preprocessing, Z.D. was responsible for the methodology design, and S.T. drafted the manuscript. All authors read and revised the final manuscript. 
Funding: This study was supported by the National Key Technology R\&D Program of China under Grant Nos. 2013BAK05B01 and 2013BAK05B02; the National Natural Science Foundation of China (Nos. 41571491, 41371495, 61631011 and 41877520); the China Special Fund for Meteorological Research in the Public Interest (No. GYHY201506001-6); the Special Fund for Science and Technology for Research Investigation (No. 2017FY101301-4); the Fundamental Research Funds for the Central Universities of China (2412016KJ046); and the Program of Introducing Talents of Discipline to Universities (B16011).

Acknowledgments: The authors would like to thank the Data Center for Resources and Environmental Sciences, Chinese Academy of Sciences (RESDS, http:/ / www.resdc.cn) for providing the land use dataset.

Conflicts of Interest: The authors declare no conflict of interest.

\section{References}

1. Mooney, H.A.; Duraiappah, A.; Larigauderie, A. Evolution of natural and social science interactions in global change research programs. Proc. Natl. Acad. Sci. USA 2013, 110, 3665-3672. [CrossRef] [PubMed]

2. Sterling, S.M.; Ducharne, A.; Polcher, J. The impact of global land-cover change on the terrestrial water cycle. Nat. Clim. Chang. 2013, 3, 385-390. [CrossRef]

3. Tian, H.; Chen, G.; Zhang, C.; Liu, M.; Sun, G.; Chappelka, A. Century-scale responses of ecosystem carbon storage and flux to multiple environmental changes in the southern United States. Ecosystems 2012, 15, 674-694. [CrossRef]

4. Meyfroidt, P.; Lambin, E.F.; Erb, K.H.; Hertel, T.W. Globalization of land use: Distant drivers of land change and geographic displacement of land use. Curr. Opin. Environ. Sustain. 2013, 5, 438-444. [CrossRef]

5. Lambin, E.F.; Baulies, X.; Bockstael, N. Land-Use and Land-Cover Change: Implementation Strategy; IGBP Report No.48/IHDP Report No.10; IGBP: Stockholm, Sweden, 1999.

6. IGBP Secretariat. GLP Science Plan and Implementation Strategy; IGBP Report No. 53/IHDP Report No.19; IGBP: Stockholm, Sweden, 2005.

7. Turner, B.L., II; Lambin, E.F.; Reenberg, A. The emergence of land change science for global environmental change and sustainability. Proc. Natl. Acad. Sci. USA 2007, 104, 20666-20671. [CrossRef] [PubMed]

8. Rindfuss, R.; Walsh, S.; Turner, B.L.; Fox, J.; Mishra, V. Developing a science of land change: Challenges and methodological issues. Proc. Natl. Acad. Sci. USA 2004, 101, 13976-13981. [CrossRef] [PubMed]

9. Gutman, G.; Janetos, A.C.; Justice, C.O.; Moran, E.F.; Mustard, J.F.; Rindfuss, R.R. Land change science. Int. Encycl. Hum. Geogr. 2004, 6, 107-111.

10. He, C.Y.; Shi, P.J.; Chen, J.; Zhou, Y.Y. A study on land use/cover change in Beijing area. Geogr. Res. 2001, 20, 679-687.

11. Pontius, R.G., Jr.; Shusas, E.; McEachern, M. Detecting important categorical land changes while accounting for persistence. Agric. Ecosyst. Environ. 2004, 100, 251-268. [CrossRef]

12. Takada, T.; Miyamoto, A.; Hasegawa, S.F. Derivation of a yearly transition probability matrix for land-use dynamics and its applications. Landsc. Ecol. 2010, 25, 561-572. [CrossRef]

13. Romero-Ruiz, M.H.; Flantua, S.G.A.; Tansey, K.; Berrio, J.C. Landscape transformations in savannas of northern South America: Land use/cover changes since 1987 in the Llanos Orientale's of Colombia. Appl. Geogr. 2012, 32, 766-776. [CrossRef]

14. Liu, R.; Zhu, D.L. Methods for detecting land use changes based on the land use transition matrix. Resour. Sci. 2010, 32, 1544-1550.

15. Qiao, W.; Sheng, Y.; Fang, B.; Wang, Y. Land use change information mining in highly urbanized area based on transfer matrix: A case study of Suzhou, Jiangsu Province. Geogr. Res. 2013, 32, 1497-1507.

16. Pontius, R.G.; Boersma, W.; Castella, J.C.; Clarke, K.; Nijs, T.D.; Dietzel, C. Comparing the input, output, and validation maps for several models of land change. Ann. Reg. Sci. 2008, 42, 11-37. [CrossRef]

17. Krajewski, P.; Solecka, I.; Mastalska-Cetera, B. Landscape change index as a tool for spatial analysis. J. IOP Mater. Sci. Eng. 2017, 245, 072014. [CrossRef]

18. Solecka, I.; Raszka, B.; Krajewski, P. Landscape analysis for sustainable land use policy: A case study in the municipality of Popielów, Poland. Land Use Policy 2018, 75, 116-126. [CrossRef]

19. Zhang, L.; Yang, G.F.; Liu, J.P. The dynamic changes and hot spots of land use in Fushun city from 1987 to 2012. Sci. Geogr. Sin. 2014, 34, 185-191. 
20. Aldwaik, S.Z.; Pontius, R.G., Jr. Intensity analysis to unify measurements of size and stationarity of land changes by interval, category, and transition. Landsc. Urban Plan. 2012, 106, 103-114. [CrossRef]

21. Huang, J.L.; Pontius, R.G., Jr.; Li, Q.S.; Zhang, Y. Use of intensity analysis to link patterns with processes of land change from 1986 to 2007 in a coastal watershed of southeast China. Appl. Geogr. 2012, 34, 371-384. [CrossRef]

22. Zhou, P.; Huang, J.; Pontius, R.G., Jr.; Hong, H. Land classification and change intensity analysis in a coastal watershed of southeast China. Sensor 2014, 14, 11640-11658. [CrossRef] [PubMed]

23. Mallinis, G.; Koutsias, N.; Arianoutsou, M. Monitoring land use/land cover transformations from 1945 to 2007 in two peri-urban mountainous areas of Athens metropolitan area, Greece. Sci. Total Environ. 2014, 490, 262-278. [CrossRef] [PubMed]

24. Sun, G.N.; Wang, M.H. Study on relation and distribution between vegetative coverage and land degradation in Inner Mongolia. J. Arid Land Resour. Environ. 2008, 22, 140-144.

25. Xu, G.C.; Kang, M.Y.; Li, Y. Analysis of land use change and its driving force in Xilingol league. Resour. Sci. 2011, 33, 690-697.

26. Zhan, J.Y.; Deng, X.Z.; Yue, T.X.; Bao, Y.H.; Zhao, T.; Ma, S.N. Land use change and its environmental effects in the farming-pasturing interlocked areas of Inner Mongolia. Resour. Sci. 2004, 26, 80-88.

27. Zhang, F.; Wang, Q.; Wang, W.J.; Shen, W.M.; Luo, H.J.; Liu, X.M. Analyzing land use change in ecotone between forest and grass in Inner Mongolia. Resour. Sci. 2006, 28, 52-58.

28. Zhang, Y.H.; Luo, Y.; Liu, J.Y.; Zhuang, D.F. Land use changes and its effect on landscape ecology in Hetao irrigated areas, Inner Mongolia. Resour. Sci. 2005, 27, 141-146.

29. Li, Q.F.; Hu, C.Y.; Wang, M.J. Analysis on the cause of eco-environmental deterioration in Xilinguole typical grassland region and counter measures. Acta Sci. Nat. Univ. NeiMongol 2003, 34, 166-172.

30. Sun, Y.L.; Guo, P.; Yan, X.D. Dynamics of vegetation cover and its relationship with climate change and human activities in Inner Mongolia. J. Nat. Resour. 2010, 25, 407-414.

31. Shi, Z.J.; Gao, J.X.; Xu, L.H. Effect of vegetation on changes of temperature and precipitation in Inner Mongolia, China. Ecol. Environ. Sci. 2011, 20, 1594-1601.

32. Liu, J.Y.; Kuang, W.H.; Zhang, Z.X.; Xu, X.L. Spatiaotemporal characteristics, patterns and causes of land-use changes in China since the late 1980s. J. Geogr. Sci. 2014, 24, 195-210. [CrossRef]

33. Liu, J.Y.; Zhang, Z.X.; Xu, X.L.; Kuang, W.H.; Zhou, W.C.; Zhang, S.W.; Li, R.; Yan, C.; Yu, D.; Wu, S.; et al. Spatial patterns and driving forces of land use change in China during the early 21st century. J. Geogr. Sci. 2010, 20, 483-494. [CrossRef]

34. Pontius, R.G., Jr.; Gao, Y.; Giner, N.M.; Kohyama, T.; Osaki, M.; Hirose, K. Design and interpretation of intensity analysis illustrated by land change in Central Kalimantan, Indonesia. Land 2013, 2, 351-369. [CrossRef]

35. Manandhar, R.; Odeh, I.O.A.; Pontius, R.G., Jr. Analysis of twenty years of categorical land transitions in the lower Hunter of New South Wales, Australia. Agric. Ecosyst. Environ. 2010, 135, 336-346. [CrossRef]

36. Gitau, M.; Bailey, N. Multi-layer assessment of land use and related changes for decision support in a coastal zone watershed. Land 2012, 1, 5-31. [CrossRef]

37. Ma, J.; Ji, C.L.; Zhang, Y.K.; Li, J.J. Cluster analysis of land use change of China's western region. China Popul. Resour. Environ. 2012, 22, 149-152.

38. Yan, L.J.; Zhang, E.H. The response of theoretical stocking rate in northern farming-pastoral transitional zone to climate change-an example of Dingxi County. Pratacult. Sci. 2005, 22, 8-10.

39. Mu, S.; Zhou, S.; Chen, Y.; Li, J.; Ju, W.; Odeh, I.O.A. Assessing the impact of restoration-induced land conversion and management alternatives on net primary productivity in Inner Mongolian grassland, China. Glob. Planet. Chang. 2013, 108, 29-41. [CrossRef]

40. Zhang, A.M. Analysis on the current status and the changes of land use in Hulunbuir, Inner Mongolia. China Land Sci. 2011, 25, 43-48.

41. Chen, H.Y.; Shao, Q.Q.; An, R. Study on land use/cover changes in the Inner Mongolia Autonomous region from 1980s to 2005. J. Geo-Inf. Sci. 2013, 15, 225-232. [CrossRef] 
42. Zhang, J.; Zeng, H. Analysis of land use/cover change in Inner Mongolia using MODIS data. J. Arid Land Resour. Environ. 2015, 29, 31-36.

43. Pelorosso, R.; Chiesa, S.D.; Tappeiner, U.; Leone, A.; Rocchini, D. Stability analysis for defining management strategies in abandoned mountain landscapes of the Mediterranean basin. Landsc. Urban Plan. 2011, 103, 335-346. [CrossRef] 